\title{
Prevalence of Babesia gibsoni Infection in Dogs of Puducherry Region
}

\author{
B. Subhash Chandra ${ }^{1 *}$, K. Rajkumar ${ }^{1}$, S.S. Das ${ }^{2}$, P. Vijayalakshmi ${ }^{1}$ and \\ A. Abiramy Prabavathy ${ }^{1}$
}

${ }^{1}$ Department of Veterinary Medicine, Teaching Veterinary Clinical Campus, Rajiv Gandhi Institute of Veterinary Education and Research, Puducherry - 605009, India

${ }^{2}$ Department of Veterinary Parasitology, Rajiv Gandhi Institute of Veterinary Education and Research, Puducherry - 605009, India

*Corresponding author

\section{A B S T R A C T}

Keywords

Babesia gibsoni,

Prevalence,

Rhipicephalus sanguineus

Article Info

Accepted:

12 February 2018

Available Online:

10 March 2018
The current study was conducted in Teaching Veterinary Clinical Campus, RIVER, Puducherry over a period of six months to determine the prevalence of Babesia gibsoni infection among dogs. Sixty-eight dogs were suspected for B. gibsoni infection in the present study and were subjected for diagnosis using conventional and molecular techniques. Ticks were collected from the dogs with $B$. gibsoni infection for identification. The current study reveals that the prevalence of B. gibsoni as $13.2 \%$ and all the ticks collected from $B$. gibsoni infected dogs were identified as Rhipicephalus sanguineus species.

\section{Introduction}

Canine babesiosis is caused by intraerythrocytic parasites belonging to the genus Babesia. Babesia species were identified as intra-erythrocytic micro-organisms in Rumania by Dr. Victor Babes in $19^{\text {th }}$ century in cattle as the cause of bovine haemoglobinuria or red water fever (SolanoGallego and Baneth, 2011) which was subsequently named Babesia bovis. The first record of canine Babesia infection in Europe was made in Italy in 1895 not long after the detection of the bovine disease (Roncalli Amici, 2001). In India B. gibsoni was first identified in 1910 in dogs and jackals which is currently considered to be endemic in Asia, Africa, Australia, Europe and the United States (Ikadai et al., 2004). Babesia species infect a variety of domestic and wild animals and humans with worldwide distribution and global significance (Solano-Gallego and Baneth, 2011). B. canis and B. gibsoni are the only species found to be present in India, where several reports indicate that B. gibsoni was more prevalent (Selvaraj et al., 2010; Vijayalakshmi, 2011 and Suresh et al., 2017). Babesia canis is a large form of piriform (teardrop shaped) organism with 2.5-5.0 $\mu \mathrm{m}$ in size, whereas small pleomorphic organisms 
of size 1.0-2.5 $\mu \mathrm{m}$, which appears as oval or signet ring form are termed as Babesia gibsoni (Conrad et al., 1991).

Babesia gibsoni is primarily a tick-transmitted haemoparasitic protozoa (Adachi et al., 1993). Rhipicephalus sanguineus, Haemaphysalis bispinosa, $H$. longicornis and $H$. leachi are the ticks responsible for transmission of $B$. gibsoni (Beugnet and Moreau, 2015). In non Asian countries, transmission occurs through bites of infected dogs, ingested blood or during fighting as in Pit bull dogs (Schnittger et al., 2012). Transmission through bite wounds, saliva or ingested blood or blood transfusion (Stegeman et al., 2003), contaminated equipment and transplacental transmission (Fukumoto et al., 2005) were also reported.

\section{Materials and Methods}

Sixty-eight dogs which were suspected to have Babesia gibsoni infection based on history and clinical observation at Teaching Veterinary Clinical Campus, Rajiv Gandhi Institute of Veterinary Education and Research, Puducherry.

The dogs were subjected for routine clinical laboratory evaluation including peripheral blood smear examination and PCR.
Detailed examination was carried out for presence of ticks on the animal body and the ticks, if present were collected and subjected for identification of the species. The ticks collected were immediately processed for identification with DPX mount and were observed under light microscope with $4 x$ magnification.

\section{Results and Discussion}

Out of 68 dogs that were suspected for Babesia gibsoni infection at TVCC, RIVER, nine were turned out to be positive for $B$. gibsoni infection either by blood smear examination or by PCR. Prevalence of Babesia gibsoni infection in Puducherry region was $13.2 \%$ (Fig. 1) among the tickborne diseases.

PCR showed greater sensitivity in diagnosing infection when compared to conventional methods. Nine dogs showed positive on agarose gel electrophoresis with bands noticed at 672 bp (Fig. 1).

Out of nine positive dogs, most of the dogs (78 \%) were infested with ticks, whereas fewer dogs $(22 \%)$ had no ticks on their body. Ticks collected from seven dogs were identified as Rhipicephalus sanguineus (Fig. 2 and 3).

Fig.1 Agarose Gel Electrophoresis of amplified product; Lane 1: negative control;

Lane 2: 100 bp ladder and Lane 3 to 9: positive samples

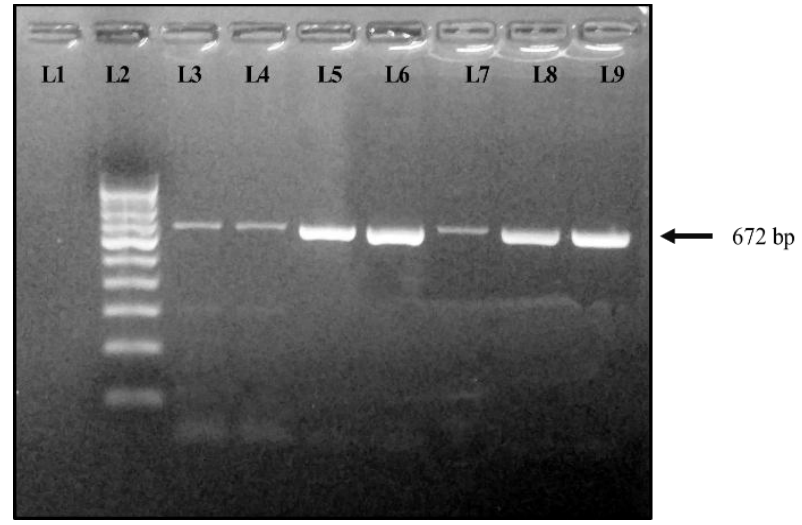


Fig.2 Dorsal view of Rhipicephalus sanguineus collected from a Dog affected with babesiosis (4x)

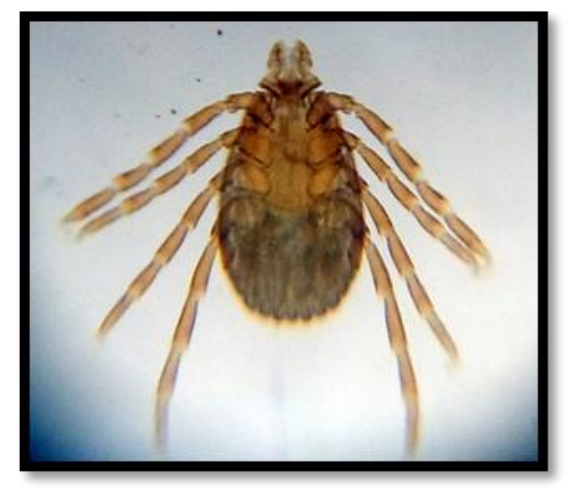

Fig.3 Ventral view of Rhipicephalus sanguineus collected from a Dog affected with babesiosis $(4 \mathrm{x})$

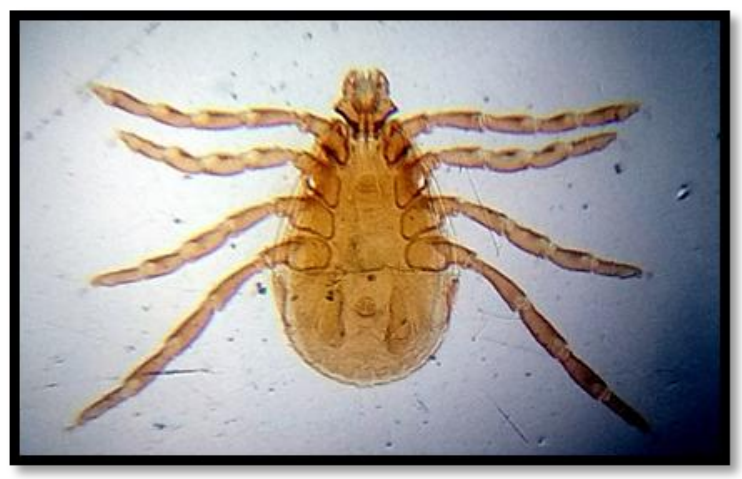

Beugnetand Moreau (2015) who opined that $R$. sanguineus was responsible for transmission of B. gibsoni in tropical climatic conditions and Soulsby (1982) reported that Rhipicephalus sanguineus was abundant in hot and humid periods of the year, thus resulting in the higher incidence of haemoprotozoan infections in warm months during warmer seasons. The present study was conducted in Puducherry region from the months between April to August during which the climate was hot and humid, which was likely to be suitable environment for the ticks to thrive.

The prevalence of Babesia gibsoni infection among tickborne diseases of dogs was $13.2 \%$ and the ticks responsible for transmission were identified as Rhipicephalus sanguineus.
Tick control measures in dogs should be highly recommended in order to control $B$. gibsoni infection.

\section{Acknowledgement}

The authors are grateful to the Dean, Rajiv Gandhi Institute of Veterinary Education and Research, Puducherry, Head, Department of Veterinary Medicine and Head, Department of Veterinary Parasitology for providing necessary facilities for the work.

\section{References}

Adachi, K., Ueno, C. and Makimura, S. (1993). Immunosuppression in dogs naturally infected with Babesia gibsoni. J. Vet. Med. Sci. 55:503-505. 
Beugnet, F and Moreau, Y. (2015). Babesiosis, Rev. Sci. Tech. Off. Int. Epiz., 34: 627-639

Conrad, P., Thomford, J., Yamane, I., Whiting, J., Bosma, L., Uno, T., Holshuh, H. J. and Shelly. S. (1991). Hemolytic anaemia caused by Babesia gibsoni infection in dogs. J. Am. Vet. Med. Assoc. 199:601-605.

Fukumoto, S., Suzuki, H., Igarashi, I. and Xuan, X., (2005). Fatal experimental transplacental Babesia gibsoni infections in dogs. Int. J. Parasitol. 35: 1031-1035.

Ikadai, H., Tanaka, H., Shibahara, N., Matsuu, A., Uechi, M., Itoh, N., Oshiro, V., Kudo, N., Igarashi, I. and Oyamada, T. (2004). Molecular Evidence of Infections with Babesia gibsoni Parasites in Japan and Evaluation of the Diagnostic Potential of a LoopMediated Isothermal Amplification Method; J. Clinical Microbiol. 42:2465-2469

Roncalli Amici, R., (2001). The history of Italian parasitology. Vet. Parasitol. 98: 3-30.

Schnittger, L., Rodriguez, A.E., Christensen, M.F. and Morrison, D.A. (2012).
Babesia: A world emerging; Infection, Genetics and Evolution 12: 1788-1809.

Selvaraj, P., Senthil Kumar, K, Vairamuthu, S., Prathaban, S. and Srinivasan, S. R. (2010). Babesia gibsoni - An emerging challenge in canine pediatric practice in Chennai. Tamilnadu J. Vet. \& Animal Sciences. 6: 122-124.

Solano-Gallego, L. and Baneth, G. (2011). Babesiosis in dogs and catsExpanding parasitological and clinical spectra; J. Vet. Parasitol. 181: 48-60.

Stegeman, J.R., Birkenheuer, A.J., Kruger, J.M., Breitschwerdt, E.B., (2003). Transfusion-associated Babesia gibsoni infection in a dog. J. Am. Vet. Med. Assoc. 222: 959-963.

Suresh, G., Sushma, C., Singla, L. D. and Randhawa, C. S. (2017). Clinicohaemato-biochemical changes in naturally occurring canine babesiosis in Punjab, India. Malaysian J. Vet. Research. 8: 37-44.

Vijayalakshmi, P. (2011). Evaluation of clinic-pathological alterations and therapeutic efficacy of babesiosis in dogs. Thesis submitted to Tamil Nadu Veterinary and Animal Sciences University, Chennai.

\section{How to cite this article:}

Subhash Chandra, B., K. Rajkumar, S.S. Das, P. Vijayalakshmi and Abiramy Prabavathy, A. 2018. Prevalence of Babesia gibsoni Infection in Dogs of Puducherry Region. Int.J.Curr.Microbiol.App.Sci. 7(03): 1275-1278. doi: https://doi.org/10.20546/ijcmas.2018.703.151 